\title{
Myofascial release versus Mulligan sustained natural apophyseal glides' immediate and short-term effects on pain, function, and mobility in non-specific low back pain
}

\author{
Vignesh Bhat $\mathbf{P}^{1}$, Vivek Dineshbhai Patel ${ }^{\text {Corresp., } 1}{ }^{1}$, Charu Eapen ${ }^{1}$, Manisha Shenoy $^{2}$, Steve Milanese ${ }^{3}$ \\ ${ }^{1}$ Department of Physiotherapy, Kasturba Medical College, Manipal Academy of Higher Education, Mangalore, Karnataka, India \\ 2 Department of Physical Therapy, Hamad Medical Corporation, Doha, Qatar \\ 3 International Centre for Allied Health Evidence, University of South Australia, Adelaide, South Australia, Australia \\ Corresponding Author: Vivek Dineshbhai Patel \\ Email address: vivek.patel@manipal.edu
}

Background: Myofascial release (MFR) and Mulligan Sustained Natural Apophyseal Glides (SNAGs) are manual therapy techniques routinely practiced in the management of non-specific low back pain (NSLBP)., As a solo intervention or along with other therapies, both methods have reported positive results for individuals with NSLBP. However, which technique improves NSLBP-related pain, restricted range of motion (ROM) and disability, warrants further research.

Objective: To study the comparative effects of MFR and SNAGs on pain, disability, functional ability, and lumbar ROM in NSLBP.

Method: A parallel-group study was conducted at tertiary care hospitals. Sixty-five Sub-acute or chronic NSLBP patients were allocated to receive strengthening exercises along with either MFR $(n=33)$ or SNAGs $(n=32)$ for six treatment sessions over one week. An independent assessor evaluated outcome measures such as the Visual Analog Scale (VAS), Patient-Specific Function Scale (PSFS), and ROM at baseline, immediate (after $1^{\text {st }}$ treatment), and short-term (post-sixth day of the intervention). The Modified Oswestry disability index (MODI) was assessed at baseline and short-term.

Results: Within-group analysis found clinically and statistically significant $(p<0.05)$ changes for VAS and PSFS at immediate and short-term for both the groups. The lumbar extension also showed improvement immediately and in the short-term. Improvement in Lumbar flexion was seen only in the SNAGs group over the short-term. A statistically significant improvement was seen for MODI in both the groups but was not clinically significant in the MFR group. The analysis observed no statistically significant difference ( $p$ $>0.05$ ) between the groups at both the immediate and short-term.

Conclusions: Pain and restricted function associated with NSLBP can be improved using SNAGs or MFR, along with strengthening exercises. For limited lumbar flexion ROM, Mulligan SNAGs have a better outcome than MFR over the short-term. Hence, both manual therapy techniques can be incorporated along with exercises for immediate and short-term management of sub-acute to chronic NSLBP. [(https://ctri.nic.in) number- CTRI/2018/12/016787] 
1 Myofascial release versus Mulligan sustained natural apophyseal glides' immediate and

2 short-term effects on pain, function, and mobility in non-specific low back pain.

3 Vignesh Bhat $\mathrm{P}^{1}$, Vivek D Patel ${ }^{2}$, Dr. Charu Eapen ${ }^{3}$, Manisha P Shenoy ${ }^{4}$, Steve Milanese ${ }^{5}$

$4 \quad$ Post graduate, Department of Physiotherapy, Kasturba Medical College, Manipal Academy of

5 Higher Education, Mangalore

$6 \quad{ }^{2}$ Assistant Professor, Department of Physiotherapy, Kasturba Medical College, Manipal

7 Academy of Higher Education, Mangalore

$8 \quad{ }^{3}$ Professor and HOD, Department of Physiotherapy, Kasturba Medical College, Manipal

9 Academy of Higher Education, Mangalore,

$10{ }^{4}$ Physiotherapy specialist, Hamad Medical Corporations, Doha, Qatar

$11{ }^{5}$ Associate Professor, International Centre for Allied Health Evidence, University of South

12 Australia, Adelaide, SA, Australia

14 Corresponding Author

15 Mr. Vivek D Patel

16 Assistant Professor, Department of Physiotherapy, Kasturba Medical College, Manipal Academy

17 of Higher Education, Mangalore

$18 \quad \mathrm{Tel}+91-8050338884$

19 vivek.patel@manipal.edu 
22

23

24

25

26

27

\section{Abstract}

Background: Myofascial release (MFR) and Mulligan Sustained Natural Apophyseal Glides (SNAGs) are manual therapy techniques routinely practiced in the management of non-specific low back pain (NSLBP)., As a solo intervention or along with other therapies, both methods have reported positive results for individuals with NSLBP. However, which technique improves NSLBP-related pain, restricted range of motion (ROM) and disability, warrants further research.

Objective: To study the comparative effects of MFR and SNAGs on pain, disability, functional ability, and lumbar ROM in NSLBP.

Method: A parallel-group study was conducted at tertiary care hospitals. Sixty-five Sub-acute or chronic NSLBP patients were allocated to receive strengthening exercises along with either MFR ( $n=33)$ or SNAGs $(n=32)$ for six treatment sessions over one week. An independent assessor evaluated outcome measures such as the Visual Analog Scale (VAS), Patient-Specific Function Scale (PSFS), and ROM at baseline, immediate (after $1^{\text {st }}$ treatment), and short-term (post-sixth day of the intervention). The Modified Oswestry disability index (MODI) was assessed at baseline and short-term.

Results: Within-group analysis found clinically and statistically significant $(p<0.05)$ changes for VAS and PSFS at immediate and short-term for both the groups. The lumbar extension also showed improvement immediately and in the short-term. Improvement in Lumbar flexion was seen only in the SNAGs group over the short-term. A statistically significant improvement was seen for MODI in both the groups but was not clinically significant in the MFR group. The 
42 analysis observed no statistically significant difference $(p>0.05)$ between the groups at both the

43 immediate and short-term.

44 Conclusions: Pain and restricted function associated with NSLBP can be improved using

45 SNAGs or MFR, along with strengthening exercises. For limited lumbar flexion ROM, Mulligan

46 SNAGs have a better outcome than MFR over the short-term. Hence, both manual therapy

47 techniques can be incorporated along with exercises for immediate and short-term management

48 of sub-acute to chronic NSLBP.

49 [(https://ctri.nic.in) number- CTRI/2018/12/016787]

50

51 Keywords: Mulligan SNAGs; Myofascial release; Non-specific low back pain; strengthening

52 exercises

53

\section{Implications for practice}

55 - Manual therapy techniques such as MFR and SNAGs can be considered for short-term

56 management of NSLBP related pain, disability, and functional improvement.

57 - Restricted sagittal plane lumbar ROM can be addressed better with the Mulligan SNAGs

58 technique than the MFR technique in NSLBP.

59

60

\section{Introduction}


61 Low back pain (LBP) is a debilitating health condition, ranked first in musculoskeletal disease

62 burden worldwide[1,2]. It is reported to have an $18.3 \%$ mean point prevalence and $30.8 \%$ one-

63 month prevalence.[3] According to the Global Burden of Disease study, LBP emerged as a

64 primary cause for years lived with disability (YLD) for all age groups in both sexes.[1] From

651990 to 2007, YLDs due to LBP increased by 30\%, with a further increase of $17 \%$ in the last

66 decade.[1]

67

68

69

70

71

72

73

74

75

76

77

Approximately $10 \%$ of LBP cases have an identifiable pathology, while the remaining $90 \%$ are non-specific LBP (NSLBP), reflecting LBP of unknown underlying pathology, characterized by pain, muscle tension, and stiffness between $12^{\text {th }}$ rib and inferior gluteal fold.[3]. Based on duration, LBP can be categorized as acute (less than six weeks), sub-acute (six to twelve weeks), and chronic (more than twelve weeks).[4]

One proposed mechanism underpinning NSLBP involves changes in lumbosacral proprioception and core muscle recruitment patterns due to atrophy of the lumbar stabilizers[5] and gluteus maximus[6] along with other hip muscles weakness.[7] The gradual decrease in motor control leads to uncontrolled and abnormal tissue loading on the myofascial complex,[8,9] stressing the lumbar spine leading to pain.[5]

The primary line of management for NSLBP includes analgesics and physical therapy interventions $[3,10]$. The routine physical therapy interventions are transcutaneous electrical nerve stimulation, low-level LASER therapy, manual therapy,[11] back schools, exercise, and timely review.[10,11] Despite the range of interventions available, NSLBP leads to chronic loss of health by limiting activity participation and loss of function, potentially resulting in prolonged work disability.[4] Manual therapies such as Mulligan mobilization,[12-18] McKenzie 
83 exercises,[14] Maitland mobilization,[15,16], and Myofascial release therapy (MFR)[8,9,19-22]

84 are used routinely in clinical practice for the management of NSLBP.

85 The Mulligan concept is based on the theory that minor position faults of articulating joints'

86 surfaces following injury or strain result in a painful and restricted, range of motion

87 (ROM).[11,12] Mulligan Sustained Natural Apophyseal Glides (SNAGs) technique adds a

88 passive accessory glide, parallel to the joint plane using a vertebral spinous process or transverse

89 process, during which the patient performs the previously painful or restricted active

90 movement.[12-18,23] Stimulation of mechanical receptors by spinal mobilization activates

91 large-diameter nerve fibers leading to activation of the pain gate mechanism.[24] At the central

92 level, descending pain pathways may be facilitated via the midbrain's periaqueductal grey

93 matter.[24] These descending neurons may release the primary mediators' opioids, nor-

94 adrenaline, and serotonin, modulating pain, reducing the muscle spasm, and improving restricted

95 lumbar movements.[16,24]

96 A systematic review indicated moderate level evidence of Mulligan technique for short-term

97 effect on LBP associated pain and disability [11]. Studies in this review delivered SNAGs in

98 addition to conventional therapy, including stretching and back extensor strengthening,

$99[12,15,16]$, and thoracic postural exercises.[15,17] Immediate and short term benefits of SNAGs

100 as a standalone treatment is reported in patients with NSLBP[13] as well as healthy

101 individuals[23] compared to sham SNAGs. Mulligan SNAGs found superior to McKenzie

102 extension exercises to improve lumbar ROM but not for pain and disability in patients with

103 NSLBP.[14]

104 Myofascial release (MFR) is a manual technique that utilizes a superintend force in a

105 predetermined direction to stretch or optimize the myofascial complex's length and gliding 
106 properties.[8,9] MFR improves myofascial restriction by breaking intermolecular cross-links and 107 redistributing internal fluids.[8,9,19-22,24] The prolonged-release in MFR superimposes stretch 108 over joint and muscle mechanoreceptors.[22] These mechanoreceptors activate the sympathetic

109 system by somatic efferent and periaqueductal grey matter modulating the descending pain 110 pathway.[19,22]

111 Two Systematic reviews suggested emerging evidence of MFR for chronic LBP[25]; however,

112 the observed effect was not clinically significant[26]. In these reviews, MFR was given as an

113 adjunct to specific back exercises[8] and occupational therapy[19] or compared to sham

114 intervention[9] in NSLBP patients. Improvement was observed for pain, fascial mobility, and

115 functional abilities following MFR intervention among non-specific neck and back pain

116 patients[9]. MFR as a standalone treatment improved pain, performances of daily activities, and

117 fear of pain [20] and lumbar ROM in patients with NSLBP over the short-term.[21]

118 Both MFR and SNAGs have shown beneficial effects in managing NSLBP. However, a dearth of

119 evidence about the comparative effect of MFR and SNAGs as an adjunct to strengthening

120 exercises in NSLBP warrants further research. Hence, this study sought to compare the

121 (immediate and short term) effects of MFR and SNAGs as adjunct treatments in patients with

122 NSLBP.

\section{Materials \& Methods}

125 The parallel-group study was carried out at tertiary care hospitals from November 2018 to

126 March 2020. Institutional Ethics Committee, Kasturba Medical College, Mangalore granted

127 ethical approval (IEC KMC MLR 11-18/429) to carry out the study. The study design was

128 registered under the clinical trial registry of India, https://ctri.nic.in with identifier 
129 CTRI/2018/12/016787. Written and oral instructions about the study procedures, interventions,

130 and possible benefits and risks were given to the patients. Written informed consent was taken

131 from all the patients. Patients were assigned to either an intervention group in an alternate

132 sequence at a 1:1 ratio. The therapist, who delivered the intervention, did a non-concealed

133 allocation of the patients. As it is an inherent issue to manual therapy trials, the therapist could

134 not be blinded to the patient's group allocation. However, patients were blinded to the other

135 intervention group.

\section{Patients}

137 Patients referred by orthopedic surgeons for physiotherapy were recruited. Patients with

138 localized back pain with restricted/painful lumbar spine movements were screened for eligibility.

139 The inclusion criteria were sub-acute to chronic NSLBP, either gender, 18-60 years old, and a

140 minimum baseline Visual Analog Scale (VAS) score of four.[27] Patients with contraindications

141 to manual therapy interventions excluded if they presented with lumbar radiculopathy, spinal

142 pathology (fracture or tumors) or history of any spinal surgery, lumbar canal stenosis,

143 osteoporosis, pregnancy-related back pain, and spinal deformities like scoliosis or

144 kyphosis[12,24,27]. Sixty-five patients with sub-acute to chronic NSLBP were included in the

145 study after screening for eligibility criteria. After screening for eligibility, patients were

146 examined for active lumbar ROM to identify involved painful/restricted segment, which was

147 confirmed using passive accessory intervertebral movement examination in a prone position.

148 Patients' flow is highlighted in the consort flow diagram (figure 1).

\section{Outcome measures}


150 An independent blinded assessor collected all the outcome data from the patients at baseline,

151 immediately post first treatment session except MODI questionnaire, and after the sixth day of

152 intervention (short term).

153 Pain levels were assessed with the VAS. It is a $100 \mathrm{~mm}$ horizontal scale with 'no pain' and 'worst

154 possible pain' labels at the line's extremes. The VAS has demonstrated good test-retest reliability,

155 which is higher among literate $(\mathrm{r}=0.94, p<0.001)$ than illiterate $(\mathrm{r}=0.71, p<0.001)$ subjects. [28]

156 Patient-Specific Function scale (PSFS) was used to assess functional ability. The patient was

157 asked to write down three activities that were the most restricted or challenging to perform. All

158 the activities were scored on a scale of zero to ten, where 'zero' is unable to perform/challenging

159 to do, and 'ten' can do as before. Previous research on the PSFS has reported moderate to good

160 reliability with an intraclass correlation coefficient (ICC) of 0.713 , and a minimal detectable

161 change (MDC) of three, and minimal important difference (MID) of 1.2.[29]

162 Disability assessment was measured using the Modified Oswestry Disability Index (MODI)

163 questionnaire, which has ten sections and provides information on LBP's effect on the patient's

164 ability to manage everyday life. A total score was converted to percentage points. Fritz and

165 Irrgang (2001) reported a high test-retest reliability of the MODI in 67 LBP patients with an ICC

166 of 0.90 and a minimum clinically important difference (MCID) of six percentage points.[30]

167 Range of motion (ROM) was assessed using a bubble inclinometer, as described by Norkin CC

168 et al. [31]. A study on the within and between-day bubble inclinometer reliability in determining

169 standing lumbar spine ROM (Flexion, extension, and lateral flexion) in healthy individuals and

170 chronic NSLBP patients found ICCs ranged from 0.908 to 0.982.[32] Inferiorly S2 and 
171 superiorly T12 spinous process was used for double inclinometer measurement technique. The

172 patient was instructed to perform active lumbar movements without bending knees.

173 Intervention

174 A total of six intervention sessions in a week were delivered to all participants in both groups.

175 Procedure for SNAGs[33]

176 The flexion or extension glide application was decided based on the movement examination for

177 restricted lumbar ROM and pain response. The SNAGs were applied in the sitting position with

178 the patient's pelvic stabilized with a Mulligan belt at the level of the anterior superior iliac spine

179 (ASIS). The therapist's hand's ulnar aspect was used over the spinous process of the superior

180 vertebra of the involved segment for flexion glide and the inferior vertebra's spinous process for

181 extension glide. A passive accessory glide was administered and maintained until the patient

182 completed a full movement arc, which was restricted or painful earlier. The glides were given for

183 six repetitions for three sets every session. (Figure 2). The glide was administered over the

184 spinous process, where the force's amplitude was upheld within the patient's comfort, as

185 Mulligan has previously described that SNAGs should not provoke any pain.

186 Procedure for MFR[19,25]

187 The patient was positioned comfortably in prone lying. Direct MFR was administered to the

188 lower back muscles with the therapists' knuckles, and the stretch held into the end range for up to

189120 seconds or until the therapist felt giving away the taut tissues before being released. MFR

190 was delivered for ten repetitions, with a total of 20 minutes of intervention. (Figure 3)

191 Strengthening exercises[6,7,34] 
192 Strengthening exercises were prescribed for all the patients, according to the referring orthopedic 193 surgeon's direction. Both groups received strengthening exercises with two sets of ten repetitions

194 without any additional resistance. Abdominal draw-in manoeuvre to activate transverse

195 abdominis was performed in crook lying. Cat and camel exercises were carried out for lumbar 196 multifidus training in a quadruped position. Strengthening of gluteal muscles (hip abductors and

197 extensors) was performed in a side-lying and prone lying positions with straight leg raise 198 exercises without any additional resistance. Patients were also briefed about ergonomic advice on posture and lifting techniques to incorporate during routine activities.

\section{Power calculation}

201 The sample size was calculated using the $\mathrm{G}^{*}$ Power analysis software (version 3.0.10). The effect 202 size for VAS was estimated, $\mathrm{d}=20 \mathrm{~mm}$, and standard deviation $(\sigma)=26.5 \mathrm{~mm}$ from a previous 203 study. [14] With a power of $85 \%$ and $\alpha$ level of 0.05 total sample size estimated to be seventy 204 (35 in each group) considering a 10\% dropout rate.

\section{Statistical analysis}

207

208

209

210

211

212

213
An independent statistician analyzed data using SPSS Version 25.0 (SPSS Inc, Chicago, IL, USA). Data were assessed for normality using skewness and kurtosis values and observation of Q-Q plots, which indicated that non-parametric tests were required. The demographic characteristics of the patients were summarized with median and interquartile ranges. Data for the lost to follow-up patients were analyzed using the intention to treat analysis by carrying forward the value of outcome measures assessed at the last follow-up. $p$ values less than 0.05 were considered statistically significant. The Friedman rank-sum test was used to determine the 
214 within-group differences from baseline to post-treatment sessions for VAS, PSFS, and lumbar

215 ROM. Post-hoc analysis using the Wilcoxon signed-rank test with Bonferroni correction was

216 performed for time* group differences. Mann- Whitney U test was used to explore the two

217 groups' differences from baseline to immediate, and short-term.

\section{Results}

Throughout the trial phases, patients' flow is highlighted in the consort flowchart (figure 1). One hundred and sixty-seven patients were screened for eligibility, of which 102 patients were excluded based on exclusion criteria. Sixty-five patients could be recruited within the study period and allocated to either MFR ( $n=33)$ and SNAGs $(n=32)$ groups. Eight patients dropped out before the sixth session, either because they dramatically improved and discharged or migrated. Intention to treat analysis was considered to accommodate dropouts. The demographic data of all the participants are shown in Table 1. Baseline characteristics of all the outcome measures were homogenous and statistically insignificant between the groups. (Table 2) The within-group analysis identified statistically significant differences for VAS, PSFS, and extension ROM for both the groups and only for flexion ROM in the SNAGs group. (Table 3) Modified Oswestry disability index also showed statistically significant $(p<0.05)$ improvement from sixteen and fourteen points at baseline in MFR and SNAGs groups respectively to twelve 232 and eight points over the short-term.

233 Time* group: For both the groups, VAS and PSFS showed immediate and short-term improvement. Lumbar extension improved immediately and in the short term in both the groups; 
236 not immediately. Lateral flexion ROM did not show any significant change for both the groups

237 (Table 4).

238 Comparison between the groups for VAS, PSFS, and ROM showed no statistically significant

239 difference $(p>0.05)$ immediately and also in the short-term, including MODI (Table 5).

\section{Discussion}

241 This study was aimed to determine the comparative effects of MFR and SNAGs in combination

242 with strengthening exercises on pain, disability, ROM, and functional ability in NSLBP patients.

243 However, both MFR and SNAGs groups demonstrated statistically significant $(p<0.05)$

244 improvements for outcomes VAS, ROM, and PSFS, immediately and in the short-term,

245 including MODI, there were no significant differences between the groups $(p>0.05)$.

246 The clinically significant improvement was observed on VAS for pain in both SNAGs and MFR

247 group with strengthening exercises. Considering the MCID value of $20 \mathrm{~mm}$ for VAS in chronic

248 pain [35], SNAGs groups demonstrated a significant change of $30.5 \mathrm{~mm}$ immediately after the $1 \mathrm{st}$

249 treatment session and $41 \mathrm{~mm}$ over the short-term. In comparison, an MFR group improved by

$25021 \mathrm{~mm}$ immediately and $42 \mathrm{~mm}$ in the short-term.

251 Similarly to this study's findings, when Waqqar et al. compared SNAGs with other manual

252 therapy techniques like McKenzie exercises, they found both have a similar effect for pain and

253 disability.[14] Other studies also found SNAGs [17] or MFR[8,919,20,21], when administered

254 as an adjunct to occupational therapy, stretching, back strengthening exercises, and thoracic

255 postural correction exercises, have short-term beneficial effects on NSLBP. This study's findings

256 indicate that both techniques with exercise can be used to address NSLBP. Though both groups

257 improved similarly over the short-term in the present study, SNAGs were clinically superior to 
258 improve pain immediately. A study by Rezkhallah et al. has reported similar findings in non-

259 specific neck pain patients. In their research, SNAGs improved pain with more percentage points 260 than MFR [24].

261 Both MFR and SNAGs help in correcting anomalies within the elements of the movement

262 system by stimulating mechanoreceptors, which might improve the activation pattern of para-

263 spinal muscles, improving pain-free ROM. However, in the current study, only the SNAGs

264 group improved with lumbar flexion ROM, while lumbar extension improved for both the

265 groups. This finding contradicted the result in non-specific neck pain patients in which both

266 MFR and SNAGs improved neck ROM in all the planes [24].

267 In line with the finding of this study, SNAGs application had an immediate and short term effect

268 on lumbar flexion ROM among healthy individuals[23] and patients with NSLBP.[14-18]

269 Passively administered spinal accessory glide breaks adhesions, leading to increased facet joint

270 vascular supply and necessary nutrients, enhancing the soft tissue healing around the injury

271 site.[24] The application of the glides over the spinous process concentrated on correcting

272 flexion and extension positional faults and promoting pain-free physiological lumbar spine

273 movement.[11] In this study, Mulligan mobilization was delivered with a contact of the spinous

274 process, which glides both facets in the same direction. During mobilization, patients also

275 performed only sagittal plane movements of lumbar flexion or extension, as it was primarily

276 restricted movement. We hypothesize, this reason for no observed improvement in lateral

277 flexion, as it requires ipsilateral facet to move in extension with contralateral facet moving to

278 flexion and can be better-improved giving mobilization using unilateral transverse process.

279 MFR found to normalize flexion relaxation phenomenon in individuals with NSLBP[21], which 280 contradicted the observation of this study in which the MFR group did not improve with lumbar 
281 flexion ROM. However, other studies have reported that MFR as an adjunct to back school

282 along with exercises[19] and work station modifications [22] improved lumbar flexion ROM.

283 These outcomes could be related to more MFR sessions, which helps break down the scar matrix

284 and intermolecular crosslinks, redistribute internal fluids, and improve collagen extensibility.

285 These effects of MFR may help in enhancing fascial mobility and soft-tissue extensibility [22].

286 In this study, MODI demonstrated statistical $(p<0.05)$ significant difference for both MFR and

287 SNAGs groups from baseline to short-term. However, only the SNAGs group shown clinically

288 significant improvement. The MCID value for the MODI has been estimated to be six

289 points.[30] Over the short-term, the MFR group showed a gain of four points, while a change of

290 six points was observed in the SNAGs group. Rezkhallah et al. reported similar findings with the

291 SNAGs group improved more than the MFR group in non-specific neck pain patients. The more

292 significant gain observed in pain and ROM can explain the improvement in disability amongst

293 the SNAGs group compared to the MFR group.

294 Both the groups demonstrated improved function immediately and over short-term, but between

295 the group, there was no significant difference for PSFS. The change for the PSFS was 2.67 in

296 both MFR and SNAGs groups over the short-term, which was not clinically significant. Abbott

297 and Schmidt[36] and Vliet et al.[37] reported MCID values of 3.3 and 4.3, respectively, for more

298 considerable clinical change of PSFS in chronic mechanical LBP.

299

300

301

302

303

Manual therapy interventions like MFR and SNAGs stimulate mechanoreceptors located in the soft tissues and the lumbar spine's facet joints. The activity of these receptors constantly feeds CNS for neuro-reflexive muscle activation. A possible explanation that both MFR and SNAGs groups showed similar improvement could be related to these techniques' effect on seducing CNS by balancing these receptors' activity and re-establish dynamic control. 
304 Limitation:

305 Severe limitation of this trial was the non-random allocation of patients to treatment arms due to 306 the trial's lack of insurance cover.

307 The study could not complete the estimated sample size recruitment within the data collection 308 time-frame.

Conclusions

311 The current study results suggest that strengthening exercises with SNAGs or MFR techniques

312 can be considered for immediate and short-term management of pain, function, and lumbar

313 extension ROM in sub-acute to chronic NSLBP. Future trials should consider assessing the 314 long-term effects of SNAGs and MFR for improvement in lumbar ROM. Varying duration of 315 MFR hold also needs to be studied with a long-term follow-up.

316 Conflict of interest

317 The authors declare there are no conflict of interest

[1] GBD 2017 Disease and Injury Incidence and Prevalence Collaborators (2018). Global , regional, and national incidence, prevalence, and years lived with disability for 354 diseases and injuries for 195 countries and territories , 1990 - 2017 : a systematic analysis for the Global Burden of Disease Study 2017. Lancet 2018;392(10159):1789-858. doi:10.1016/S0140-6736(18)32279-7. 
325 [2] Hoy D, March L, Brooks P, Blyth F, Woolf A, Bain C, Williams G, Smith E, Vos T,

326 Barendregt J, Murray C, Burstein R, Buchbinder R. The global burden of low back pain:

327 Estimates from the Global Burden of Disease 2010 study. Ann Rheum Dis 2014;

328 73(6):968-74. https://doi.org/10.1136/annrheumdis-2013-204428.

329 [3] Maher C, Underwood M, Buchbinder R. Non-specific low back pain. Lancet 2017; 389(10070):736-47. https://doi.org/10.1016/S0140-6736(16)30970-9.

[4] Krismer M. Strategies for prevention and management of musculoskeletal conditions. Low back pain (non-specific). Best Prac Res Clin 2007;21(1):77-91. https://doi.org/10.1016/j.berh.2006.08.004.

[5] Goubert D, van Oosterwijck J, Meeus M, Danneels L. Structural changes of lumbar muscles in non-specific low back pain. Pain Physician 2016;19(7):985-1000.

[6] Jeong UC, Kim CY, Hwang-Bo G NC. The effects of gluteus muscle strengthening exercise and lumbar stabilization exercise on lumbar muscle strength and balance in chronic low back pain patients. J Phys Ther Sci 2015;27(12):3813-6. doi: 10.1589/jpts.27.3813.

[7] de Sousa CS, de Jesus FLA, Machado MB, Ferreira G, Ayres IGT, de Aquino LM, Fukuda TY, Gomes-Neto M. Lower limb muscle strength in patients with low back pain: a systematic review and meta-analysis. J Musculoskelet Neuronal Interact. 2019 Mar

[8] Ajimsha MS, Daniel B, Chithra S. Effectiveness of Myofascial release in the management of chronic low back pain in nursing professionals. Bodyw Mov Ther 2014; 18(2):273-81. https://doi.org/10.1016/j.jbmt.2013.05.007. 
347 [9] Tozzi P, Bongiorno D, Vitturini C. Fascial release effects on patients with non-specific

348 cervical or lumbar pain. Bodyw Mov Ther 2011; 15(4):405-16.

349 https://doi.org/10.1016/j.jbmt.2010.11.003.

[10] van Middelkoop M, Rubinstein SM, Kuijpers T, Verhagen AP, Ostelo R, Koes BW, van Tulder MW. A systematic review on the effectiveness of physical and rehabilitation interventions for chronic non-specific low back pain. Eur Spine J 2011;20(1):19-39. doi:10.1007/s00586-010-1518-3.

[11] Pourahmadi MR, Mohsenifar H, Dariush M, Aftabi A, Amiri A. Effectiveness of mobilization with movement (Mulligan concept techniques) on low back pain: a systematic review. Clin Rehabil 2018. Oct.32(10): 1289-98 https://doi.org/10.1177/0269215518778321.

[12] Hussien HM, Abdel-Raoof NA, Kattabei OM, Ahmed HH. Effect of Mulligan Concept Lumbar SNAG on Chronic Nonspecific Low Back Pain. J Chiropr Med 2017;16(2):94-

[13] Hidalgo B Pitance L Hall T Detrembleur C Nielens H. Short-term effects of Mulligan mobilization with movement on pain, disability, and kinematic spinal movements in patients with nonspecific low back pain. a rondomied placebo controlled trial. J Manip Physiol Ther. 38(6):365-74. doi:10.1016/j.jmpt.2015.06.013.

[14] Waqqar S, Shakil-Ur-Rehman S, Ahmad S. McKenzie treatment versus mulligan sustained natural apophyseal glides for chronic mechanical low back pain. Pakistan J Med Sci 2016;32(2):476-9. doi:10.12669/pjms.322.9127. 
Mobilization In Chronic Low Back Pain. Phys Educ Sport Sci 2018;4(12):71-84. doi:10.5281/zenodo.1471519.

[16] Elrazik RKA, Samir SM, Zaki LA, Koura GA. Mobilisation with movement versus postero-anterior mobilisation in chronic non specific low back pain. Int J PharmTech Res 2016;9(6):9-16.

[17] Tul Ain SQ, Shakil Ur Rehman S, Maryam M, Kiani SK. Effects of Sustained Natural Apophyseal Glides with and without thoracic posture correction techniques on mechanical back pain: a randomized control trial. J Pak Med Assoc 2019;69(11):1584-7. doi:10.5455/JPMA.274875

[18] Muhanna NA. Effectiveness of Snags Mobilization in Chronic Mechanical Low Back Pain. J Adv Sch Res Allied Educ 2018;15:153-8. doi:10.29070/15/57740.

[19] Saratchandran R DS. Myofascial release as an adjunct to conventional occupational therapy in mechanical low back pain. Indian J Occup Ther. 2013;45(2) 3-7

[20] Arguisuelas MD, Lisón JF, Sánchez-Zuriaga D, Martínez-Hurtado I, DoménechFernández J. Effects of Myofascial Release in Nonspecific Chronic Low Back Pain. Spine 2017;42(9):627-34. doi:10.1097/BRS.0000000000001897.

[21] Arguisuelas MD, Lisón JF, Doménech-Fernández J, Martínez-Hurtado I, Salvador Coloma P, Sánchez-Zuriaga D. Effects of myofascial release in erector spinae myoelectric activity and lumbar spine kinematics in non-specific chronic low back pain: Randomized controlled trial. Clin Biomech 2019;63:27-33. doi:10.1016/j.clinbiomech.2019.02.009.

[22] Balasubramaniam A, Ghandi V, Sambandamoorthy A. Role of myofascial release therapy 
on pain and lumbar range of motion in mechanical back pain: an exploratory investigation of desk job workers. Ibnosina J Med Biomed Sci 2013;6(2):75-80.

[23] Moutzouri M, Billis E, Strimpakos N, Kottika P, Oldham JA. The effects of the Mulligan Sustained Natural Apophyseal Glide (SNAG) mobilisation in the lumbar flexion range of asymptomatic subjects as measured by the Zebris CMS20 3-D motion analysis system. BMC Musculoskelet Disord 2008;9(1):1-9. doi:10.1186/1471-2474-9-131.

[24] Rezkallah SS, Abdullah GA. Comparison between sustained natural apophyseal glides (SNAG's) and myofascial release techniques combined with exercises in non specific neck pain. Physiother Pr Res 2018;39(2):135-45. doi:10.3233/PPR-180116.

[25] Ajimsha MS, Al-Mudahka NR, Al-Madzhar JA. Effectiveness of myofascial release: Systematic review of randomized controlled trials. J Bodyw Mov Ther 2015;19(1):102-12. doi:10.1016/j.jbmt.2014.06.001.

[26] Laimi K, Mäkilä A, Bärlund E, Katajapuu N, Oksanen A, Seikkula V, Karppinen J, Saltychev M Effectiveness of myofascial release in treatment of chronic musculoskeletal pain: a systematic review. Clin Rehabil 2018;32:440-50. doi:10.1177/0269215517732820.

[27] Amundsen PA, Evans DW, Rajendran D, Bright P, Bjørkli T, Eldridge S, Buchbinder R, Underwood M, Froud R. Inclusion and exclusion criteria used in non-specific low back pain trials: a review of randomised controlled trials published between 2006 and 2012. BMC Musculoskelet Disord 2018;19(1):113. doi:10.1186/s12891-018-2034-6.

[28] Hawker GA, Mian S, Kendzerska T, French M. Measures of adult pain: Visual Analog Scale for Pain (VAS Pain), Numeric Rating Scale for Pain (NRS Pain), McGill Pain 
412

413

Questionnaire (MPQ), Short-Form McGill Pain Questionnaire (SF-MPQ), Chronic Pain Grade Scale (CPGS), Short Form-36 Bodily Pain Scale (SF-36 BPS) and measure of Intermittent and Constant Osteoarthritis Pain (ICOAP). Arthritis Care Res 2011;63:24052. doi:10.1002/acr.20543.

[29] Hefford C. The Patient-Specific Functional Scale: Validity, Reliability, and Responsiveness in Patients With Upper Extremity Musculoskeletal Problems. J Orthop Sports Phys Ther. 2012;42(2):56-65. doi:10.2519/jospt.2012.3953.

[30] Fritz JM, Irrgang JJ. A Comparison of a Modified Oswestry Low Back Pain Disability Questionnaire and the Quebec Back Pain Disability Scale. Phys Ther 2001;81(2):776-88. doi:10.1093/ptj/81.2.776.

[31] Norkin CC, White DJ. Measurement of Joint Motion: A Guide to Goniometry. 4th ed. Philadelphia,

[32] PA: F. A. Davis Company, 2009. Sadeghi R, Mosallanezhad Z, Nodehi-Moghadam A, Nourbakhsh M, Biglarian A, Ezati K. The Reliability of Bubble Inclinometer and Tape Measure in Determining Lumbar Spine Range of Motion in Healthy Individuals and Patients Phys Treat Specif Phys Ther 2015;15(3):137-44.

[33] Mulligan B. Manual Therapy, NAGS, SNAGS MWMS etc. 5th ed. Wellington, New: Zealand: Plane View Services Limited; 2010.

[34] Sadler S, Cassidy S, Peterson B, Spink M, Chuter V. Gluteus medius muscle function in people with and without low back pain : a systematic review. BMC Musculoskelet Disord 2019;4:1-17. doi.org/10.1186/s12891-019-2833-4 
433 [35] Vela LI, Haladay DE, Denegar C. Clinical Assessment of Low-Back-Pain Treatment

$434 \quad$ Outcomes in Athletes. J Sport Rehabil 2011;20(1):74-88. doi: 10.1123/jsr.20.1.74

435 [36] Abbott JH. Minimum Important Differences for the Patient-Specific Functional Scale, 4 Phys Ther. 2014;44(8):560-4. doi:10.2519/jospt.2014.5248.

[37] Vliet DVAN, Hefford PTC, Abbott MJH. The Patient-Specific Functional Scale: 
Figure 1

CONSORT Flow Diagram 


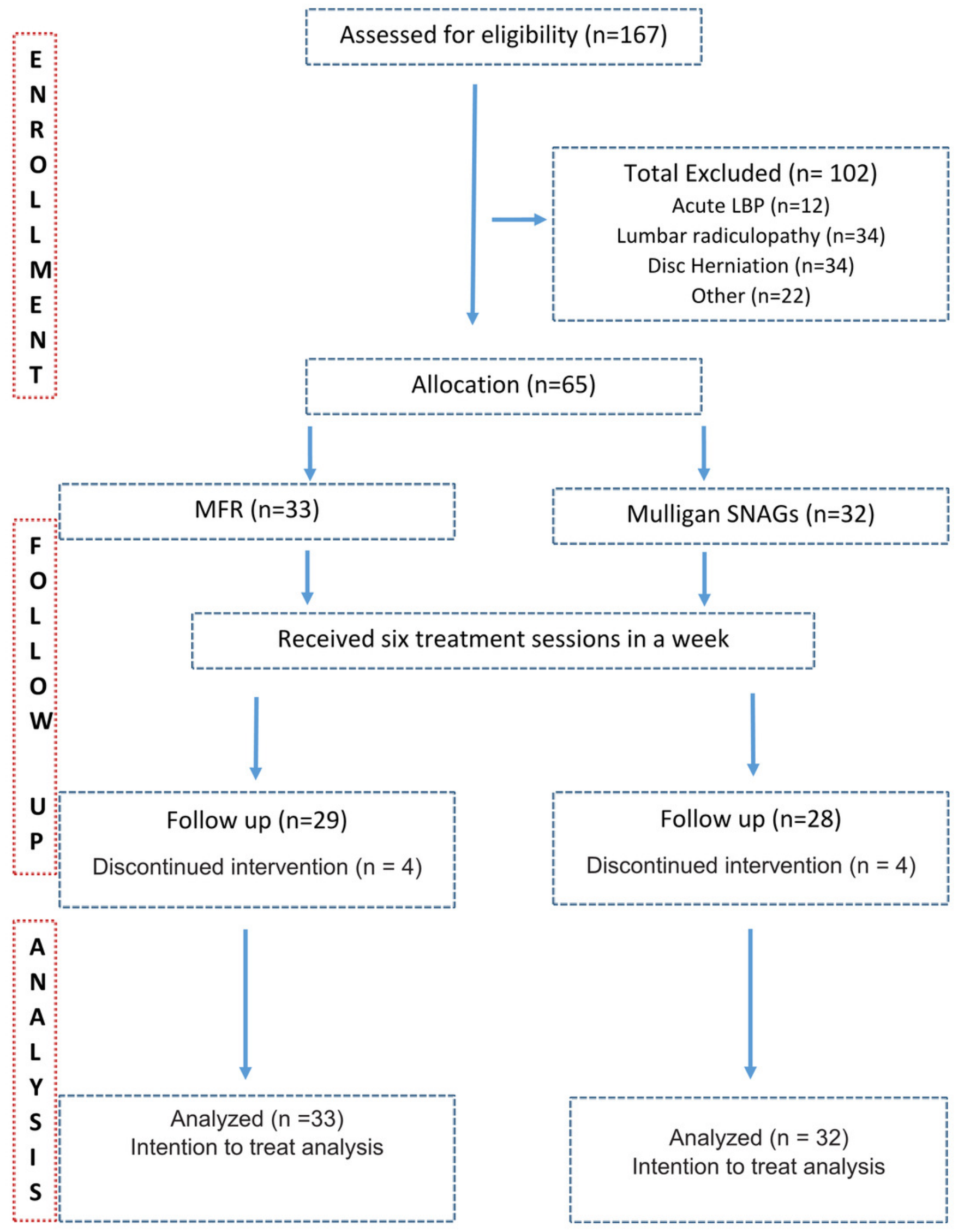


Figure 2

Mulligan SNAGs Technique

\author{
A - Starting Neutral Position \\ B - Neutral to Extension SNAGs
}




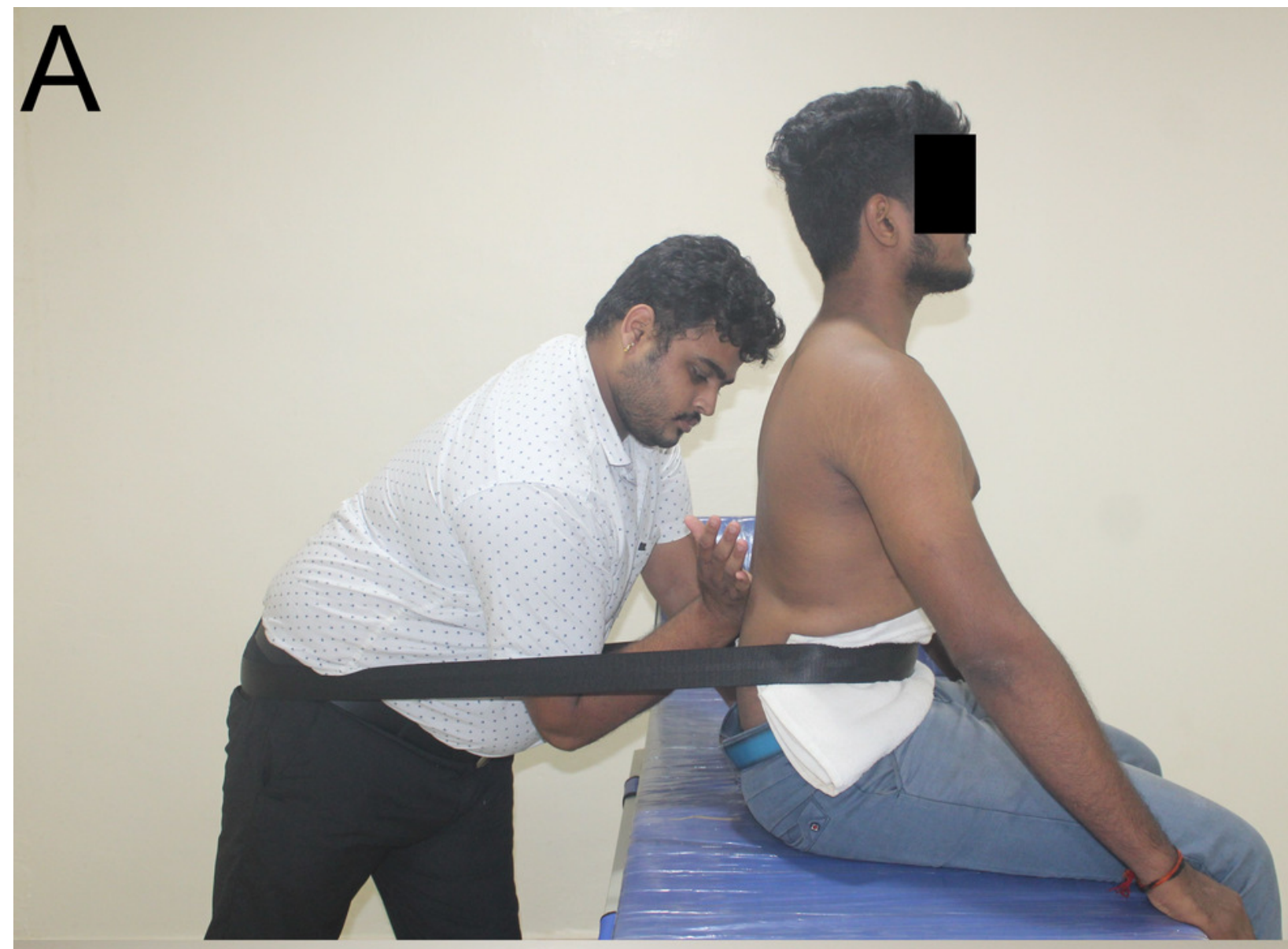

B

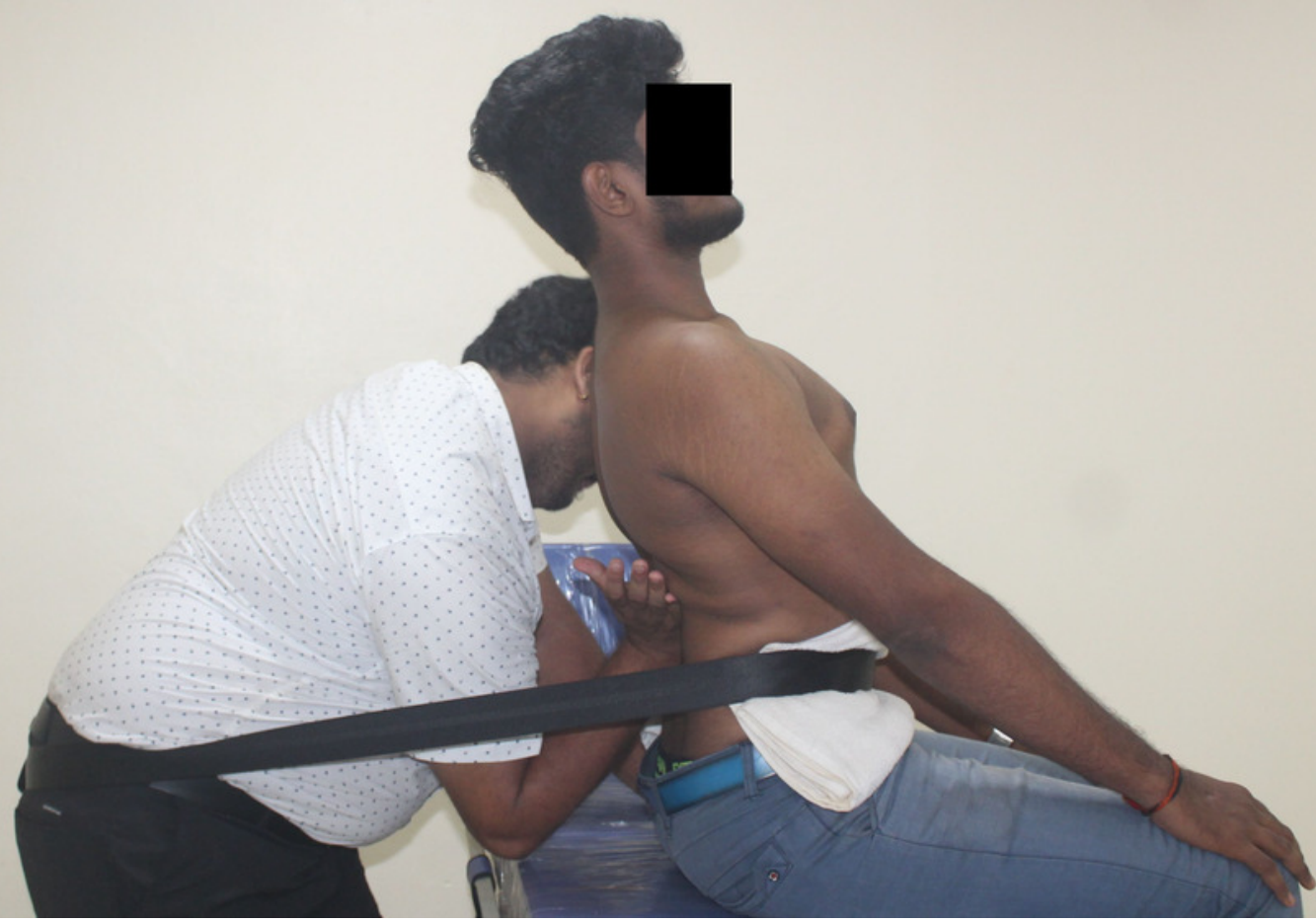


Figure 3

Myofascial Release Technique

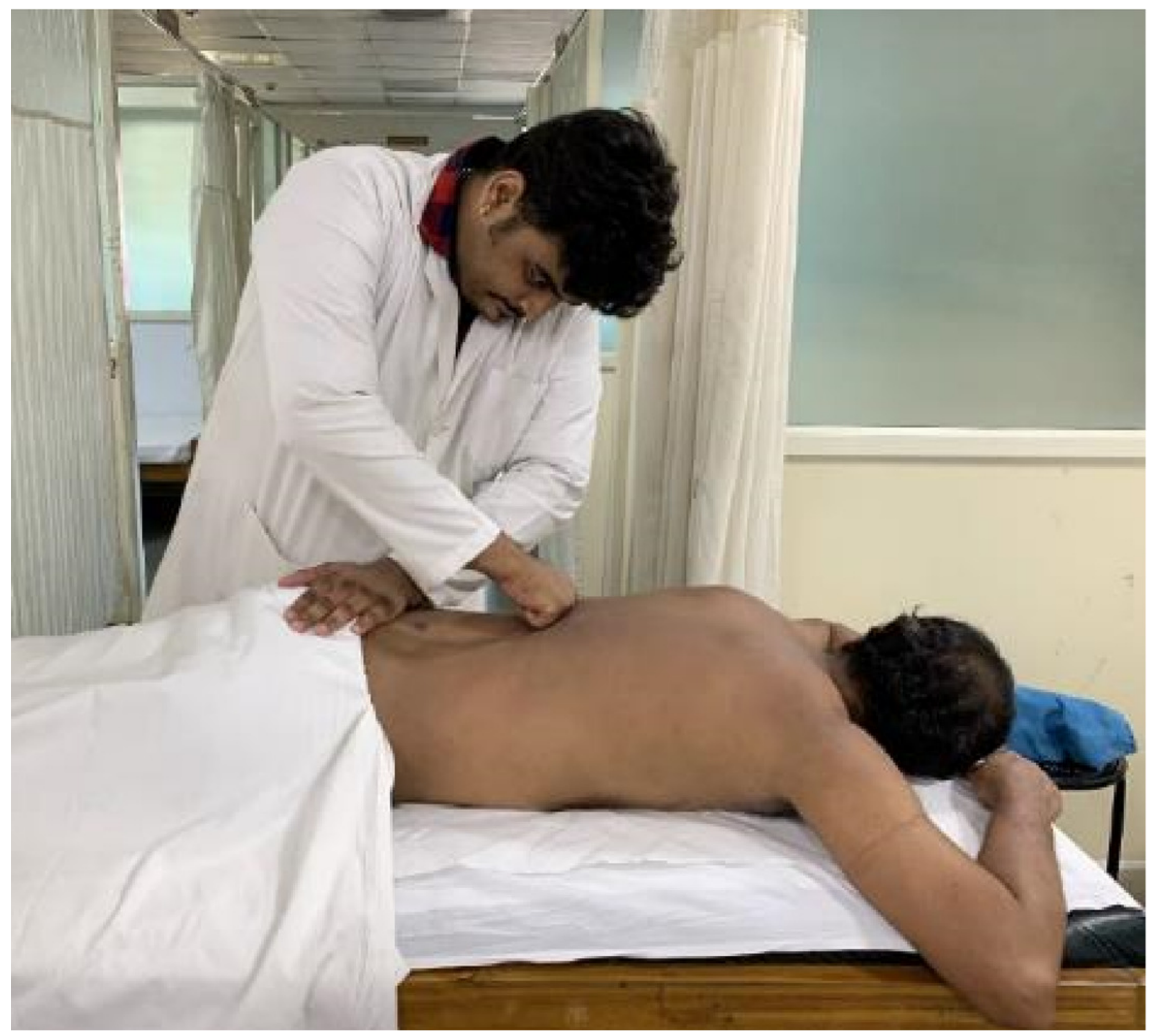


Table $\mathbf{1}$ (on next page)

Demographic details of the participants 


\begin{tabular}{|c|c|c|c|}
\hline \multicolumn{2}{|l|}{ Variables } & $\operatorname{MFR}(n=33)$ & SNAGs $(n=32)$ \\
\hline \multicolumn{2}{|c|}{ Age (years, Mean \pm SD) } & $25 \pm 7.11$ & $24.34 \pm 5.37$ \\
\hline \multirow{2}{*}{ Gender } & Male & 15 & 5 \\
\hline & Female & 18 & 27 \\
\hline \multirow{2}{*}{$\begin{array}{l}\text { Duration of LBP } \\
\text { (weeks) }\end{array}$} & Sub-acute (6-12 weeks) & 2 & 5 \\
\hline & Chronic ( $>12$ weeks) & 31 & 27 \\
\hline
\end{tabular}

3

Table 1. Demographic details of sixty-five participants

4 n- Total number of participants, SD- Standard Deviation, LBP- Low back pain

5

6

7

8

9

10 


\section{Table 2 (on next page)}

Baseline characteristics of VAS, MODI, PSFS and ROM for MFR and SNAGs groups

${ }^{*} p<0.05$ statistical significant 
Table 2. Baseline characteristics of VAS, MODI, PSFS and ROM for MFR and SNAGs groups

\begin{tabular}{|c|c|c|c|}
\hline \multirow{2}{*}{ Variables } & \multicolumn{2}{|c|}{ MEDIAN (IQR) } & \multirow{2}{*}{$p$-value } \\
\cline { 2 - 4 } & MFR & SNAGs & 0.11 \\
\hline VAS (mm) & $6.2(5.2-7.2)$ & $6.1(4.5-4.7)$ & 0.545 \\
\hline MODI (\%) & $16(12-25)$ & $14(1.5-25)$ & 0.232 \\
\hline $\begin{array}{c}\text { Flexion (degrees) } \\
\text { PSFS }\end{array}$ & $5.33(3.83-5.33)$ & $4.33(3.33-5.33)$ & 0.712 \\
\hline $\begin{array}{c}\text { Extension(degrees) } \\
\text { Left lateral } \\
\text { flexion(degrees) }\end{array}$ & $18(10-20)$ & $50(44.25-57.75)$ & 0.889 \\
\hline $\begin{array}{c}\text { Right lateral } \\
\text { flexion(degrees) }\end{array}$ & $20(15-25)$ & $16.5(10.25-25)$ & 0.595 \\
\hline
\end{tabular}




\section{Table 3 (on next page)}

Within-group analysis of VAS, PSFS, and ROM for MFR and SNAGs groups at Baseline, immediate and short-term

$* p<0.05$ statistical significant 
1 Table 3. Within-group analysis of VAS, PSFS, and ROM for MFR and SNAGs groups at 2 Baseline, immediate and short-term

\begin{tabular}{|c|c|c|c|c|c|c|}
\hline \multirow{2}{*}{ Variable } & \multirow{2}{*}{ Group } & \multicolumn{3}{|c|}{ MEDIAN (IQR) } & \multirow{2}{*}{$\begin{array}{c}\text { Friedman } \\
\text { Chi- } \\
\text { square }\end{array}$} & \multirow[b]{2}{*}{$p$-value } \\
\hline & & Baseline & Immediate & Short-term & & \\
\hline \multirow{2}{*}{ VAS (mm) } & MFR & $6.2(5.2-7.2)$ & $4.1(1.9-5.2)$ & $2(1.0-3.45)$ & 49.465 & $<0.001^{*}$ \\
\hline & SNAGs & $6.1(4.5-4.7)$ & $3.05(2.05-4.37)$ & $2(0.85-3.65)$ & 53.382 & $<0.001^{*}$ \\
\hline \multirow[b]{2}{*}{ PSFS } & MFR & $4.33(3.83-5.33)$ & $5.66(4.49-6.16)$ & $7(5.83-7.58$ & 55.197 & $<0.001 *$ \\
\hline & SNAGs & $4.33(3.33-5.33)$ & $5.33(5-6.66)$ & $\begin{array}{c}6.83(6.12- \\
7.62)\end{array}$ & 49.589 & $<0.001^{*}$ \\
\hline \multirow{2}{*}{ Flexion(degrees) } & MFR & $50(45-57.5)$ & $50(45-59)$ & $52(45.5-60)$ & 3.227 & 0.199 \\
\hline & SNAGs & $50(44.25-57.75)$ & $52.5(45-59.5)$ & $55.5(50-60)$ & 6.660 & $0.035^{*}$ \\
\hline \multirow{2}{*}{ Extension(degrees) } & MFR & $18(10-20)$ & $20(15-30)$ & $25(19-30)$ & 30.624 & $<0.001 *$ \\
\hline & SNAGs & $16.5(10.25-25)$ & $21.5(18.25-29.5)$ & $25(20-31.5)$ & 22.505 & $<0.001 *$ \\
\hline \multirow{2}{*}{$\begin{array}{l}\text { Left lateral flexion } \\
\text { (degrees) }\end{array}$} & MFR & $20(15-25)$ & $22(15-30)$ & $20(20-25)$ & 0.890 & 0.640 \\
\hline & SNAGs & $20(15-28.5)$ & $20(15-25)$ & $24.5(15-28)$ & 2.347 & 0.309 \\
\hline \multirow{2}{*}{$\begin{array}{c}\text { Right lateral } \\
\text { flexion(degrees) }\end{array}$} & MFR & $20(13-25)$ & $20(17.5-26)$ & $20(17.5-26)$ & 5.957 & 0.050 \\
\hline & SNAGs & $20(15-25)$ & $20(15-27.75)$ & $20(15.75-28)$ & 3.588 & 0.166 \\
\hline
\end{tabular}

$* p<0405$ statistical significance IQR- Inter quartile Range, VAS: Visual Analog Scale, mm- millimetre, MFR:

5 Myofascial release, SNAGs: Sustained Natural Apophyseal Glides, PSFS: Patient Specific Functional Scale, 


\section{Table 4 (on next page)}

Time*group analysis for VAS, PSFS and ROM for MFR and SNAGs groups

${ }^{* * p}<0.05$ statistical significant 
1 Table 4 time* group analysis for VAS, PSFS, and ROM for MFR and SNAGs groups

\begin{tabular}{|c|c|c|c|c|c|c|c|}
\hline Variables & Group & Factors & $\begin{array}{c}\text { Mean } \\
\text { Difference }\end{array}$ & Std. Error & $p$-value & \multicolumn{2}{|c|}{$\begin{array}{l}95 \% \text { Confidence } \\
\text { Interval }\end{array}$} \\
\hline \multirow{4}{*}{ VAS(mm) } & \multirow{2}{*}{ MFR } & Pre * Immediate & 2.503 & 0.344 & $0.0001 * *$ & 1.63 & 3.37 \\
\hline & & Pre * Post & 3.806 & 0.309 & $0.0001 * *$ & 3.02 & 4.58 \\
\hline & \multirow{2}{*}{ SNAGs } & Pre * Immediate & 2.484 & 0.0322 & $0.0001 * *$ & 1.66 & 3.3 \\
\hline & & Pre * Post & 3.544 & 0.315 & $0.0001 * *$ & 2.74 & 4.34 \\
\hline \multirow{4}{*}{ PSFS } & \multirow{2}{*}{ MFR } & Pre * Immediate & -1 & 0.175 & $0.0001 * *$ & -1.441 & -0.559 \\
\hline & & Pre * Post & -2.156 & 0.197 & $0.0001 * *$ & -2.655 & -1.658 \\
\hline & \multirow{2}{*}{ SNAGs } & Pre $*$ Immediate & -1.495 & 0.212 & $0.0001 * *$ & -2.031 & -0.959 \\
\hline & & Pre * Post & -2.751 & 0.278 & $0.0001 * *$ & -3.454 & -2.047 \\
\hline \multirow{4}{*}{$\begin{array}{l}\text { Flexion } \\
\text { (degrees) }\end{array}$} & \multirow{2}{*}{ MFR } & Pre * Immediate & -0.545 & 1.112 & 1 & -3.35 & 2.26 \\
\hline & & Pre * Post & -1.879 & 0.894 & 0.13 & -4.13 & 0.379 \\
\hline & \multirow{2}{*}{ SNAGs } & Pre * Immediate & -1.875 & 1.24 & 0.422 & -5.01 & 1.26 \\
\hline & & Pre $*$ Post & -4.594 & 1.489 & $0.013 * *$ & -8.36 & -0.82 \\
\hline \multirow{4}{*}{$\begin{array}{l}\text { Extension } \\
\text { (degrees) }\end{array}$} & \multirow{2}{*}{ MFR } & Pre $*$ Immediate & -6.03 & 1.234 & $0.0001 * *$ & -9.14 & -2.91 \\
\hline & & Pre * Post & -7.455 & 1.258 & $0.0001 * *$ & -10.63 & -4.27 \\
\hline & \multirow{2}{*}{ SNAGs } & Pre * Immediate & -5.03 & 1.522 & $0.007 * *$ & -8.88 & -1.17 \\
\hline & & Pre * Post & -7.219 & 1.42 & $0.0001 * *$ & -10.81 & -3.62 \\
\hline \multirow{4}{*}{$\begin{array}{c}\text { Left lateral } \\
\text { flexion } \\
\text { (degrees) }\end{array}$} & \multirow{2}{*}{ MFR } & Pre * Immediate & -1.27 & 1.366 & 1 & -4.72 & 2.17 \\
\hline & & Pre * Post & -0.97 & 1.413 & 1 & -4.54 & 2.6 \\
\hline & \multirow{2}{*}{ SNAGs } & Pre * Immediate & -0.375 & 0.912 & 1 & -2.68 & 1.93 \\
\hline & & Pre * Post & -1.688 & 1.283 & 0.594 & -4.93 & 1.56 \\
\hline \multirow{4}{*}{$\begin{array}{l}\text { Right lateral } \\
\text { flexion } \\
\text { (degrees) }\end{array}$} & \multirow{2}{*}{ MFR } & Pre * Immediate & -2.242 & 1.059 & 0.126 & -4.91 & 0.43 \\
\hline & & Pre * Post & -2.758 & 1.416 & 0.181 & -6.33 & 0.82 \\
\hline & \multirow{2}{*}{ SNAGs } & Pre * Immediate & -1.06 & 1.033 & 0.934 & -3.67 & 1.55 \\
\hline & & Pre * Post & -1.594 & 1.19 & 0.57 & -4.6 & 1.41 \\
\hline
\end{tabular}

$* * p<3.05$ statistical significance VAS: Visual Analog Scale, mm- millimetre, MFR: Myofascial release, SNAGs: 4 Sustained Natural Apophyseal Glides, PSFS: Patient Specific Functional Scale, 
Table 5 (on next page)

Between-group analysis of VAS, MODI, PSFS, and ROM : Immediate and over short-term ${ }^{*} p<0.05$ statistical significant 
Table 5. Between group analysis of outcomes: immediate and over short-term

\begin{tabular}{|c|c|c|c|}
\hline \multirow{2}{*}{ Variable } & \multicolumn{2}{|c|}{ MEDIAN (IQR) } & \multirow{2}{*}{$p$-value } \\
\cline { 2 - 3 } Immediate & MFR & SNAGs & \\
\hline VAS (mm) & $4.1(1.9-5.2)$ & $3.05(2.05-4.37)$ & 0.328 \\
\hline Flexion (degrees) & $50(45-59)$ & $52.5(45-59.5)$ & 0.937 \\
\hline Extension(degrees) & $20(15-30)$ & $21.5(18.25-29.5)$ & 0.889 \\
\hline Left lateral flexion (degrees) & $22(15-30)$ & $20(15-25)$ & 0.595 \\
\hline Right lateral flexion (degrees) & $20(17.5-26)$ & $20(15-27.75)$ & 0.889 \\
\hline PSFS & $5.66(4.49-6.16)$ & $5.33(5-6.66)$ & 0.388 \\
\hline Short-term & $2(0.85-3.65)$ & 0.674 \\
\hline VAS (mm) & $2(1.0-3.45)$ & $55.5(50-60)$ & 0.380 \\
\hline Flexion (degrees) & $52(45.5-60)$ & $25(20-31.5)$ & 0.731 \\
\hline Extension(degrees) & $25(19-30)$ & $24.5(15-28)$ & 0.754 \\
\hline Left lateral flexion (degrees) & $20(20-25)$ & $20(15.75-28)$ & 0.931 \\
\hline Right lateral flexion (degrees) & $20(17.5-26)$ & $8(6-15.5)$ & 0.472 \\
\hline MODI (\%) & $12(6-16)$ & $7(6.12-7.62)$ & 0.385 \\
\hline PSFS & $7(5.83-7.58$ & & \\
\hline
\end{tabular}

$3 * p<0.05$ statistical significance IQR- Inter quartile Range, VAS: Visual Analog Scale, mm- millimetre, MFR: Myofascial release, SNAGs: Sustained Natural Apophyseal

5 Glides, PSFS: Patient Specific Functional Scale, MODI: Modified Oswestry Disability Index 